\title{
Rectal mucosal morphologic abnormalities in normal subjects in southern India: a tropical colonopathy?
}

\author{
MINNIE M MATHAN AND V I MATHAN \\ From the Wellcome Research Unit, Christian Medical College Hospital, Vellore, India
}

SUMmARY Electron dense bodies and vesicles were increased in undifferentiated crypt cells and differentiated colonocytes in the rectal mucosa of healthy volunteers in southern India. In addition, in the surface colonocytes lysosomes were increased, the cells were shorter with short irregularly grouped microvilli, there was evidence of cell immaturity and a high prevalence of spiral organism infestation. There was also alterations in goblet cell mucus granules, a reticulohistiocytic response in the subluminal lamina propria and residual evidence of vascular damage. These alterations indicate a non-specific response to mucosal injury. Such changes have not been observed in the rectal mucosa of temperate zone controls and could be designated tropical colonopathy.

Morphologic abnormalities in the small intestinal mucosa in healthy populations of many tropical developing countries, associated with minor absorptive defects, is recognised as tropical enteropathy. ${ }^{1-3}$ These widely prevalent structural and functional alterations are likely to be an adaptation of the small intestinal epithelium to the contaminated environment of the tropics. ${ }^{4}$ Although the ultrastructural morphology of the rectal mucosa has been studied extensively in temperate zone controls ${ }^{5-11}$ there are no such reports from tropical regions. This paper reports the ultrastructural morphology of the rectal mucosa in a group of healthy volunteers from southern India. A 'tropical colonopathy', similar to the small intestinal lesion, was shown by abnormalities in the rectal mucosal epithelium and lamina propria in this normal population.

\section{Methods}

BIOPSIES

Rectal mucosal biopsies (two or three pieces) were obtained, at sigmoidoscopy, $8-10 \mathrm{~cm}$ from the anal verge, with the Truelove-Salt suction biopsy instrument, from 14 adult village volunteers aged 22-50 years without gastrointestinal symptoms and normal tests of intestinal absorption. None of them had had diarrhoea during the two months before biopsy.

One or two pieces of the rectal mucosa were immediately fixed in $2.5 \%$ glutaraldehyde with 0.1

Address for correspondence: Professor Minnie M Mathan. The Wellcome Research Unit, CMC Hospital, Vellore 632004 , India.

Received for publication 24 August 1984
$\mathrm{mM} \mathrm{CaCl}$ in phosphate buffer $(\mathrm{pH} 7 \cdot 4)$, postfixed in $1 \%$ phosphate buffered osmium tetroxide and embedded in Araldite. One micron thick sections were stained with toluidine blue and examined to assess histological features. Well orientated blocks of tissues where complete longitudinal crypt profiles could be identified were selected for detailed morphological study. Ultrathin sections were cut with a diamond knife and stained with saturated aqueous uranyl acetate and lead citrate for examination with a Philips EM201 electron microscope. One biopsy from each patient was processed for paraffin sections stained with haematoxylin and eosin.

For comparison with the biopsy material from southern India, Dr Gregory L Eastwood, Worcester, Massachusetts, kindly provided four biopsies from healthy adult volunteers in the United States of America. Observations on these biopsies as well as published reports from temperate climates will be referred to as temperate zone controls. Measurements were done on at least five well orientated complete sections of epithelial cells for each subject and mean values calculated.

\section{Results}

The architecture of the rectal mucosa, with epithelial cells organised in tubular glands separated by lamina propria, was similar to that reported from temperate regions (Fig. 1). At the base of crypts undifferentiated and differentiating colonocytes and endocrine cells and higher up differentiated colum710 


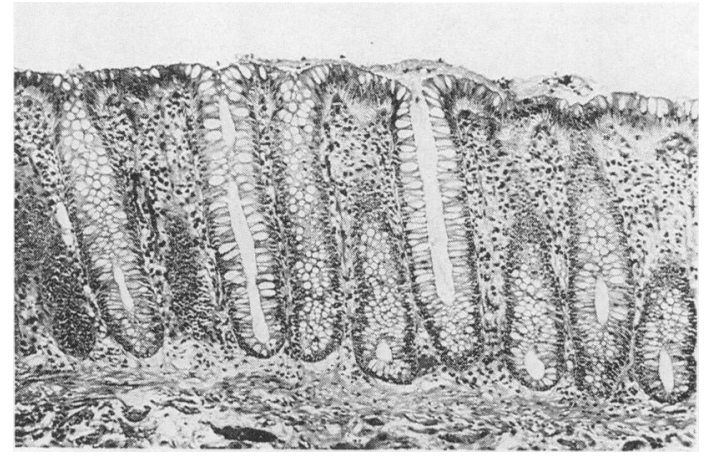

Fig. 1 Light micrograph of a well orientated rectal biopsy from a southern Indian control subject. Note increased cellularity of the lamina propria (Paraffin embedded and stained with haematoxylin and eosin, $\times 100$ original magnification)

characterise the rectal mucosa. Minimal increase in the cellularity of the lamina propria and shortening of columnar cells at the luminal area with some loss of nuclear polarity could be appreciated by light microscopy in conventional paraffin sections and in $1 \mu$ sections. In the $1 \mu$ sections, in addition, alterations in the staining density of colonocytes and vacuolation of the cytoplasm in the luminal area were also apparent (Fig. 2). Goblet cells were apparently normal. Spiral organisms, adherent to the surface colonocytes, were seen at light microscopy in nine of the biopsies.

\section{ULTRASTRUCTURAL MORPHOLOGY Undifferentiated cells}

The undifferentiated cells at the base of crypts had large, indented, basally placed nuclei, poorly formed microvilli, abundant ribosomes, with many polyribosomes and a few large mitochondria containing small dense bodies. The endoplasmic reticulum was scanty and Golgi apparatus was well developed but sparse. Round electron dense bodies and small vesicles were present in the apical cytoplasm (Fig. 3). These were usually uniformly electron dense, but some showed a clear area surrounding or to one side, while a few were less dense and appeared grey. A limiting membrane was identifiable on electron dense bodies that were less dense or had a surrounding clear space. Electron dense bodies were increased in number and more electron dense in the southern Indian control subjects compared with temperate zone controls. In four subjects electron dense bodies were markedly increased.

\section{Columnar cells}

Fully differentiated columnar cells on the free

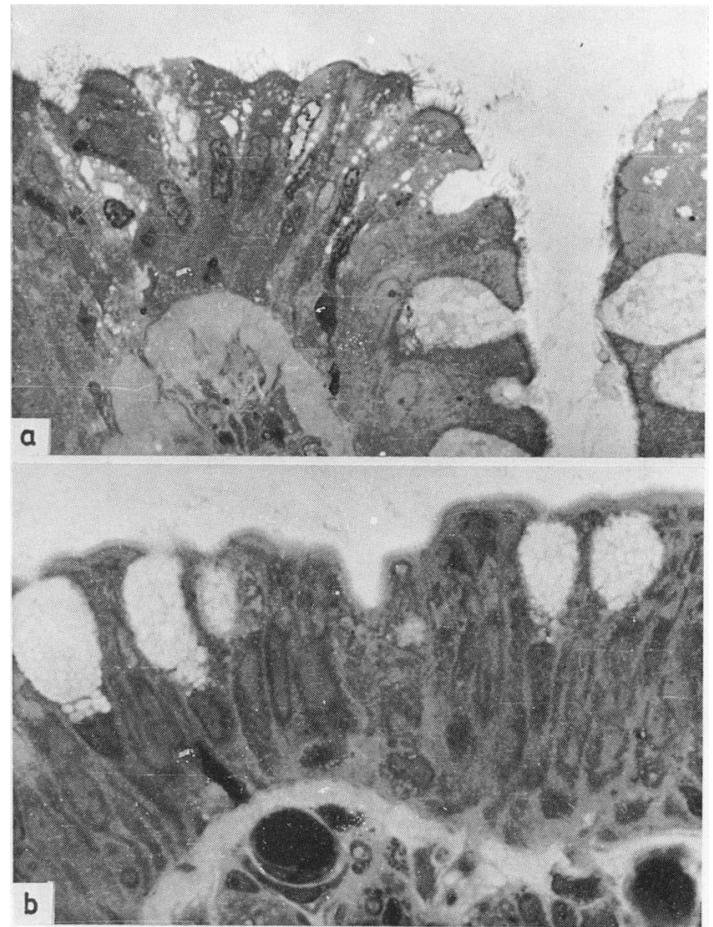

Fig. 2 (a) Rectal biopsy from southern Indian control subject. Luminal surface cells showing cytoplasmic vacuolation and variation in staining density. Nucleii are placed at different levels. Spiral organism are seen attached to microvillous border. Subepithelial reticular layer is more prominent. (b) Biopsy from western control for comparison (Araldite embedded. $1 \mu$ section stained with toluidene blue, $\times 930$ original magnification).

luminal surface, between the opening of the crypts, develop from the undifferentiated cells in the crypt base. Cellular maturation was indicated by more centrally placed nuclei, with less prominent nuclear indentation, development of microvilli with deep core rootlets extending into the apical cytoplasm, abundant glycocalyx and microvillar bodies, an increase in number with decrease in size of supraand infra-nuclear mitochondria and increasing plications of the lower half of the lateral cell membrane. Electron dense bodies and vesicles increased in number and size and became less electron dense with larger vesicles containing fine fibrillary or occasionally crystalloid material (Fig. 4). The fine fibrillary material in the vesicles was different from the more flocculent contents of the goblet cell mucus granules (Fig. 5), and resembled the glycocalyx of the microvilli and apical border of the columnar cells (Fig. 6). Large lysosomal bodies and $\mathrm{R}$ bodies with vesicular structure containing rod-like inclusions, ${ }^{12}$ 

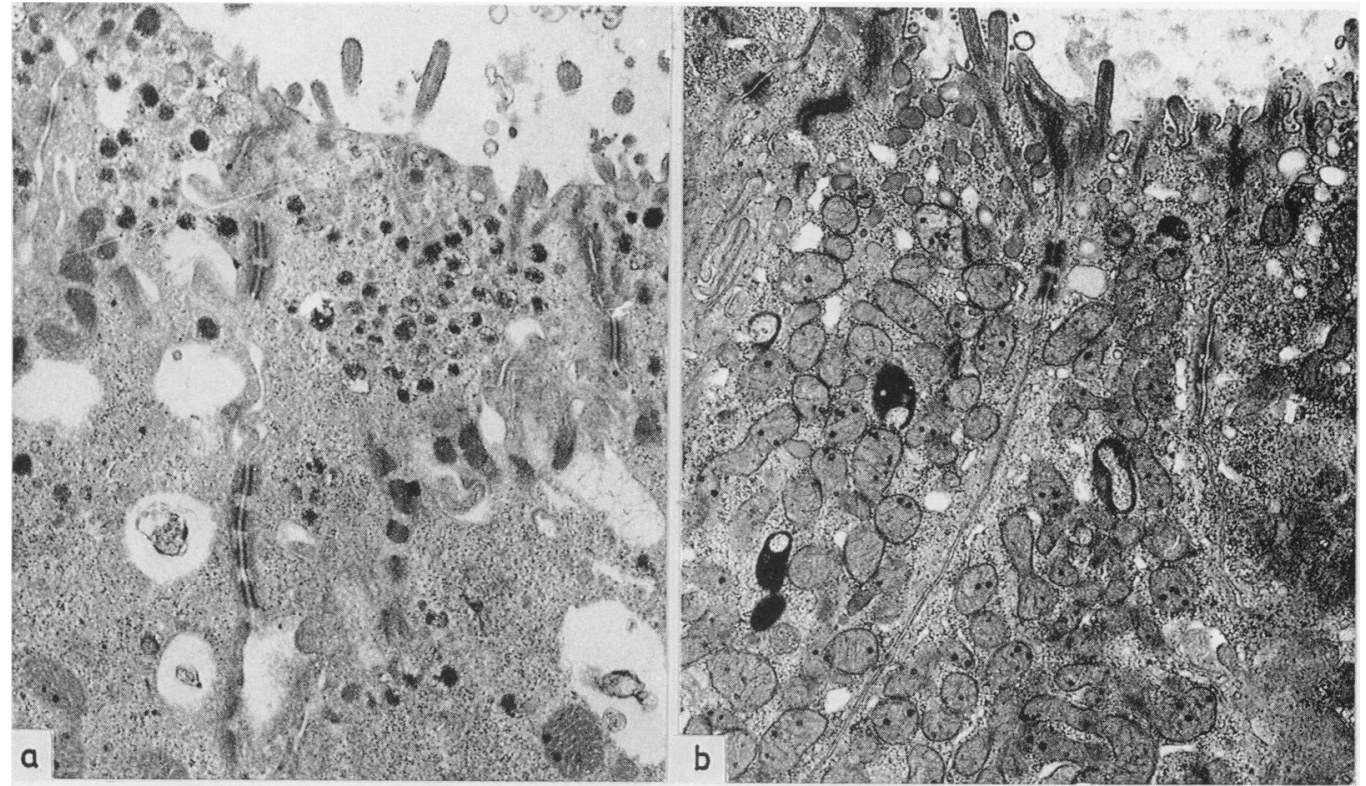

Fig. 3 (a) Apical cytoplasm of undifferentiated cell in the crypt base of southern Indian control subject with increased electron dense bodies and vesicles ( $\times 9600$ original magnification). (b) Similar cell from a western control for comparison ( $\times 9600$ original magnification).

were seen in the apical cytoplasm of columnar cells from the lower third of the crypt onwards. As the cell matured and progressed towards the upper third of the crypt secondary lysosomes and $\mathrm{R}$ bodies increased in number (Fig. 7). The luminal columnar cells were shorter $(35 \cdot 2 \pm 10 \cdot 1 \mu)$ than in the temper-

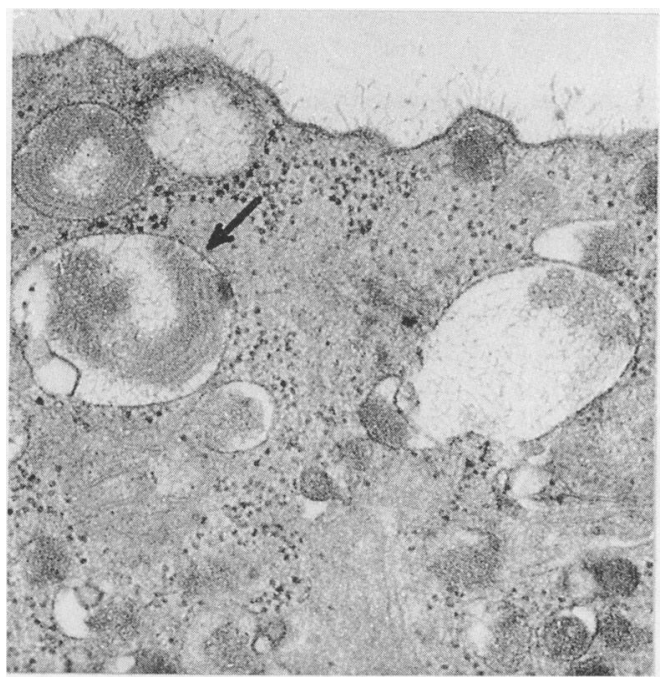

Fig. 4 Apical border of columnar cell from lower third of crypt with vesicles containing cystalline material (arrow) ( $\times 38500$ original magnification). ate zone controls $(48 \cdot 3 \pm 6 \cdot 7 \mu)$, with irregularly grouped shorter microvilli (southern India $0.83 \pm 0.41 \mu$, temperate zone $1 \cdot 14 \pm 0.25 \mu)$ and nuclei often arranged at different levels in contrast with the orderly arrangement near the basal half of the cells in the temperate zone controls (Fig. 8). The electron density of the columnar cells in the luminal area varied. Some cells were very electron dense with condensed nuclei and cytoplasm, large mitochondria with a dense matrix and a submicrovillus dense band. Majority of the cells, took a paler stain and were less electron dense with numerous small mitochondria. These mitochondria were less abundant and the interdigitations of lateral cell borders in the basal half less well developed in the southern Indian subjects on comparison to temperate zone controls.

In nine of the 14 biopsies from southern India numerous spiral organisms were seen embedded in the apical cytoplasm of the luminal cells and cells at crypt mouths. Microvilli of the cells with spiral organisms were short and irregularly grouped with increased spherical microvillus bodies and irregular protrusions between microvilli (Fig. 9). In four biopsies with heavy spiral organism infestation, the proportion of columnar cells compared with goblet cells was increased and they contained more electron dense bodies in the lower third of the crypt and increased apical vesicles higher up. 


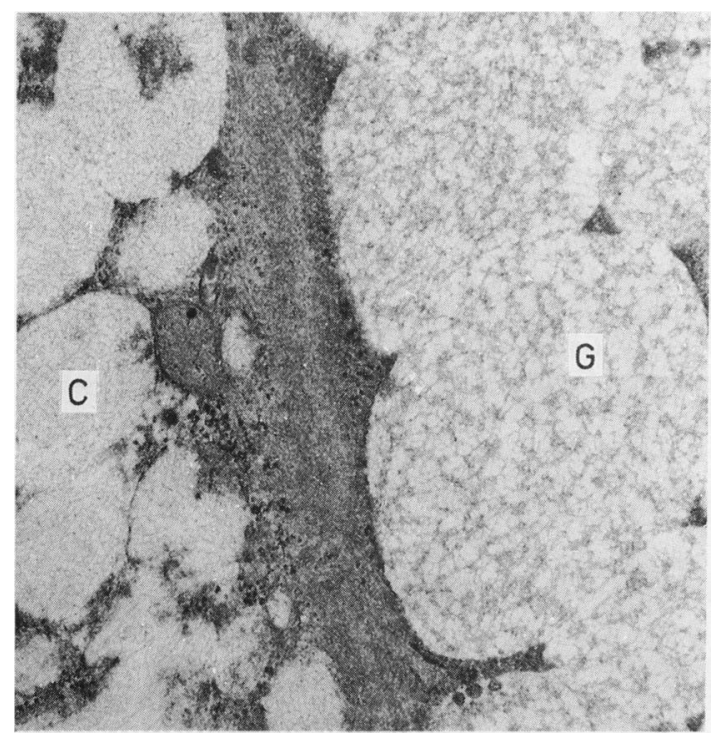

Fig. 5 Cells from upper third of crypt with goblet cell mucus granules $(G)$ showing flocculent material and columnar cell vesicles $(C)$ containing fine fibrillary material ( $\times 38500$ original magnification).

Goblet cells

In four subjects there was marked variation in the density of the mucus granules of goblet cells with some of the granules being extremely electron dense (Fig. 10). In these four patients there was also a marked increase in electron dense bodies and vesicles in the columnar epithelial cells along the

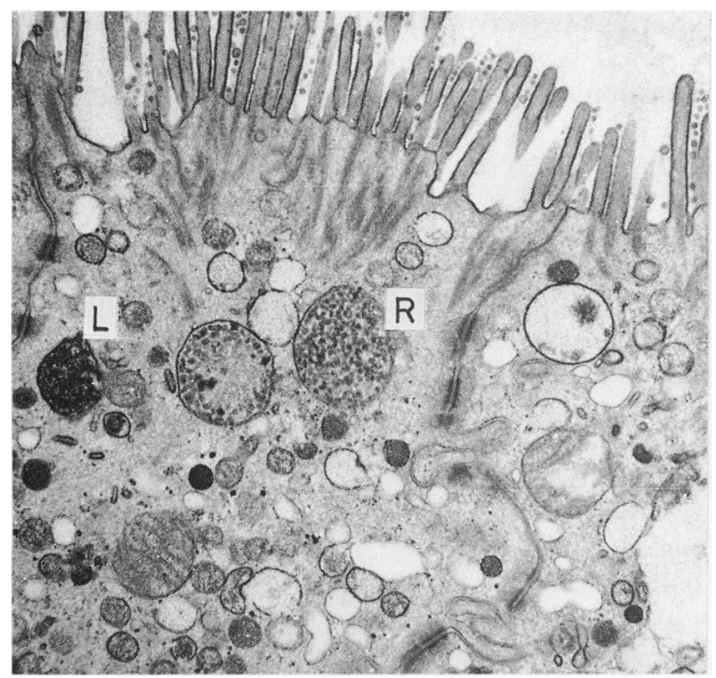

Fig. 7 Apical cytoplasm of columnar cells from upper third of crypt with increase in electron dense bodies. Also seen are $R$ bodies $(R)$, secondary lysosomes $(L)$, and many microvillous bodies ( $\times 27200$ original magnification) .

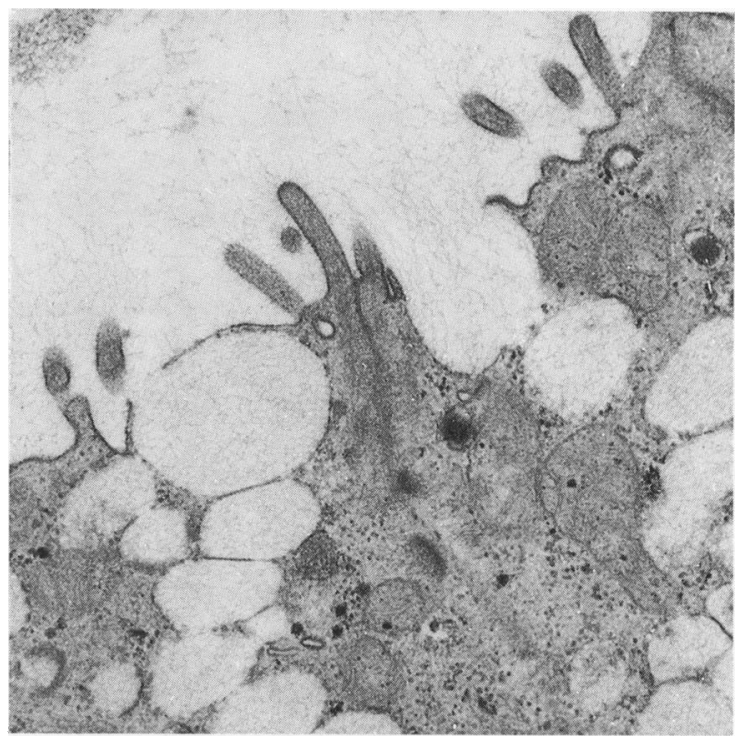

Fig. 6 Luminal border of same columnar cell as in Fig. 5, shows the vesicles emptying onto the surface with contents similar to that of the glycocalyx of the microvilli $(\times 38500$ original magnification).

length of the crypt and at the free luminal border. Spiral organisms were found in only two of these biopsies.

\section{Lamina propria}

The cellularity of the lamina propria was increased compared with temperate zone controls, with increase in plasma cells, large subluminal macrophages with heterogenous lysosomal bodies, eosinophils and mucosal mast cells. In three of the volunteers occasional neutrophil polymorphs were also present. The plasma cells showed increased activity and plasmacytolysis in the deeper layers of the lamina propria. There was also degranulation of scattered eosinophils and mucosal mast cells. Subluminal reticulin was increased compared with temperate zone controls.

Striking changes were seen in the blood vessels of the lamina propria with reduplication of the basal lamellae in a varying number of venules and capillaries (Fig. 11). While these changes were seen in a small number of vessels in all the biopsies, in three biopsies a few blood vessels near the base of the crypts also showed organised thrombi occluding the lumen (Fig. 12). In one subject there was focal rupture of venules with platelet adhesion and effusion of red blood cells into the lamina propria with dehaemoglobinisation. In addition, in this biopsy, in occasional capillaries damaged endothelial cells were present. 

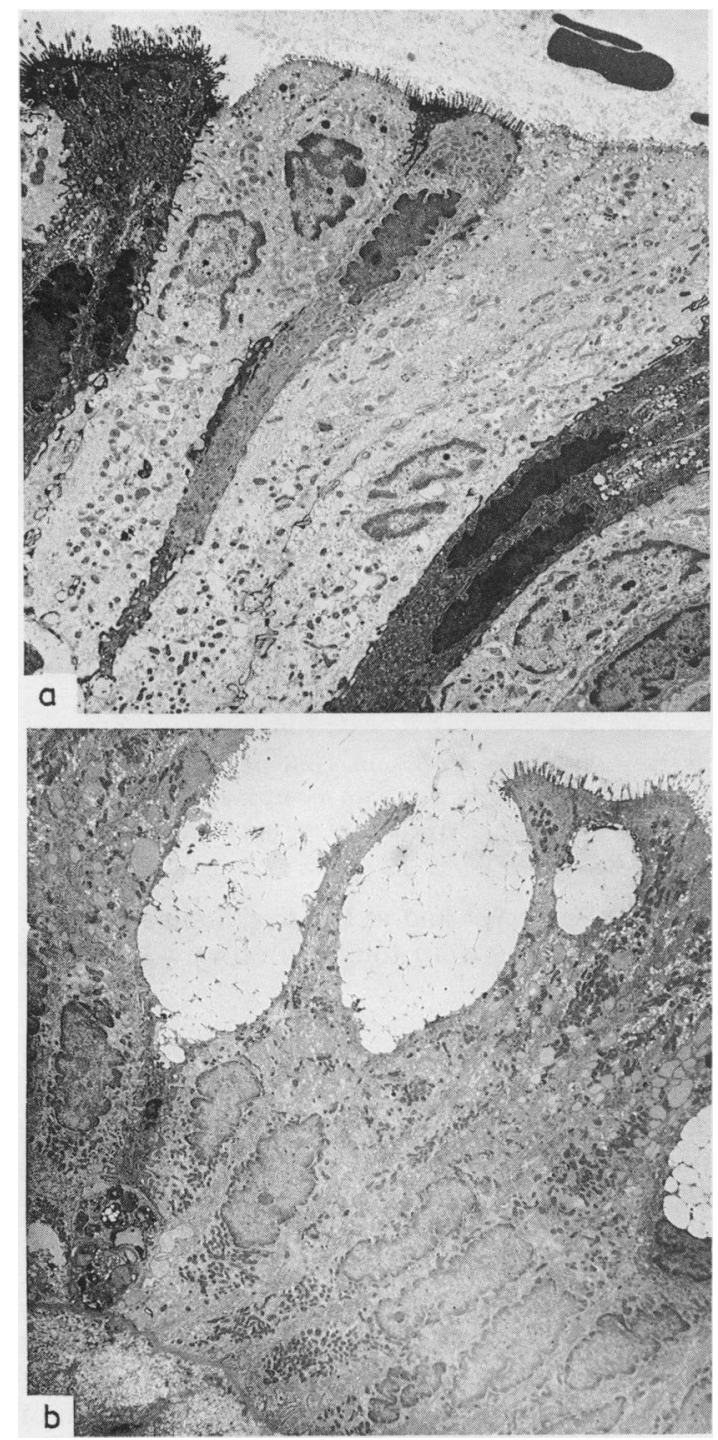

Fig. 8 (a) Luminal border away from site of extrusion. The cells show variation in electron density. Nuclei are placed in different levels. Microvilli are short and irregular. Lateral membrane shows few plications $(\times 2900$ original magnification). (b) Similar area from a western control. Note the abundant mitochondria, supra and infra nuclear, and well developed microvilli and lateral membrane plications $(\times 2900$ original magnification $)$.

\section{Discussion}

Increased electron dense bodies and vesicles in the apical cytoplasm of undifferentiated crypt cells and differentiated columnar cells, with increase in lysosomes and $\mathrm{R}$ bodies in the columnar epithelial cells even in the lower third of the crypts and heterogenous electron density of the mucus granules of goblet cells found in rectal mucosal epithelial cells in biopsies obtained from volunteer control subjects in southern India were not seen in temperate zone controls. In addition, the luminal epithelial cells were shorter with shorter microvilli and less mature with decrease in the plication of the lower part of the lateral cell membrane and fewer mitochondria. There was also a high prevalence of spiral organisms attached to the surface of the luminal epithelial cells and alterations in the lamina propria vasculature, cellularity and subluminal reticulin content,

It has been suggested that there is only one epithelial cell type in the colon and that the dark staining epithelial cells are goblet cells that have discharged their mucus granules. ${ }^{11}$ The lighter stained epithelial cells are presumed to be derived from these cells when they absorb water from the lumen. Dark staining epithelial cells are found scattered among lighter staining cells in the hen coprodeum. Freeze fracture studies showed rod shaped organelles in the cell membranes of dark staining cells in the coprodeum and it has been suggested that these cells are specialised for sodium absorption. ${ }^{13}$ Similar intramembrane organelles have been demonstrated in about a fifth of colonic epithelial cells in primates ${ }^{14}$ although no functional correlates were made. Further work is necessary on the morphogenesis of these dark staining epithelial cells and to understand their significance and function.

Increased electron dense bodies and vesicles and differing electron density of goblet cell granules reported here are similar to changes reported in transitional mucosa adjacent to colonic carcinoma and polyps in temperate zone subjects. ${ }^{15}$ Similar changes were found in the normal epithelium of the ascending and proximal transverse colon but were seldom seen in the rectal mucosa of temperate zone controls. ${ }^{11}$ In the monkey colon electron dense bodies in the crypt basal cells gradually matures to less dense vesicles and finally discharges material with a striking resemblance to glycocalyx. ${ }^{16}$ Silver methanamine and immunohistochemical stains suggest that electron dense bodies may contain glycoproteins and immunoglobulins and may also contribute to the surface coat material. ${ }^{8}{ }^{16-19}$ The increased electron dense bodies and vesicles in the southern Indian rectal mucosa would therefore appear to be a response of the epithelial cells to damage, by increasing secretions and production of glycocalyx.

The prevalence of spiral organisms in rectal biopsies is extremely low in the temperate zone populations, although it was high in a West African 

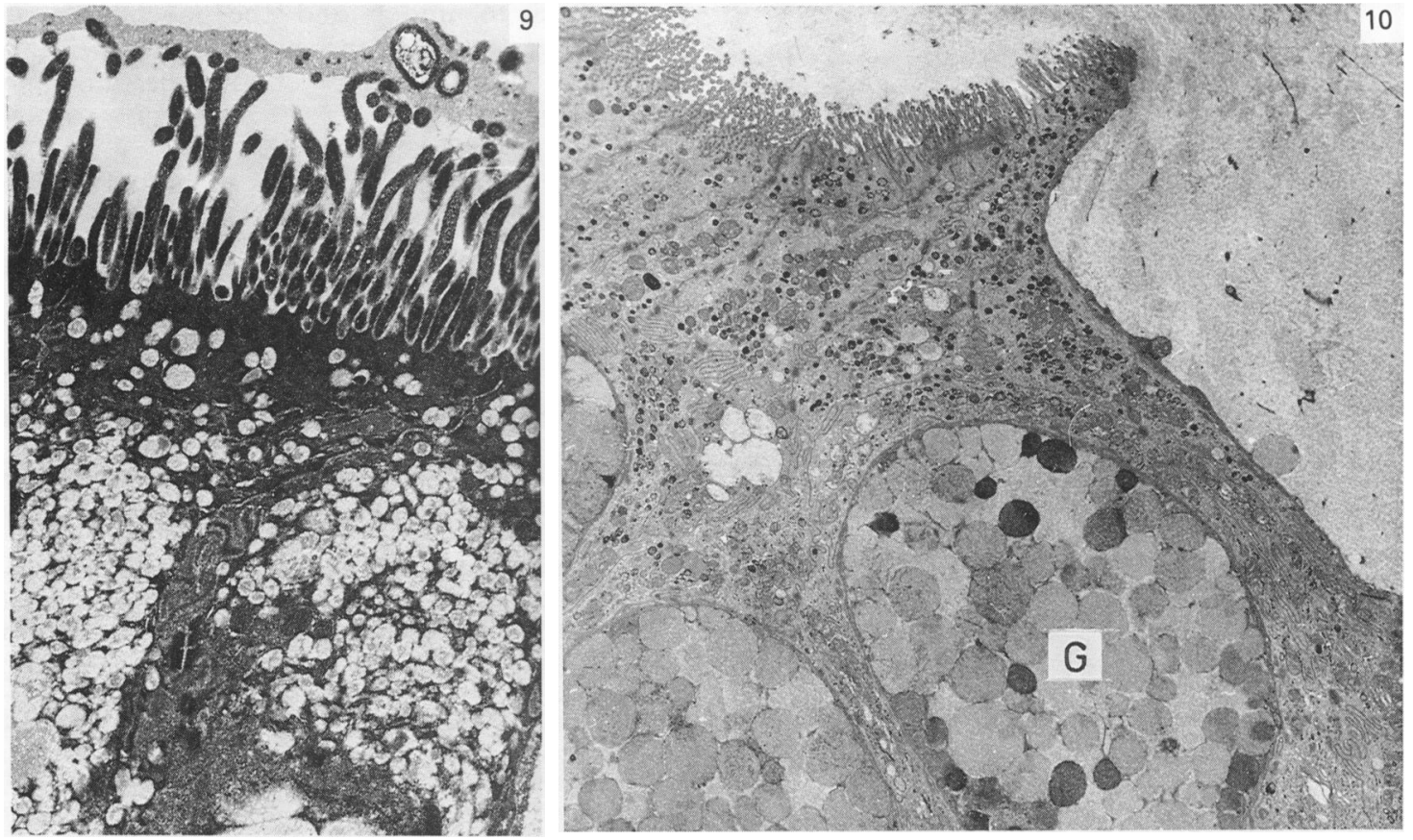

Fig. 9 Apical border of luminal cells heavily infested with spiral organisms. Microvilli are short and sparse. Cross section of bacteria seen in the surface mucus. Apical cytoplasm shows many vesicles ( $\times 9500$ original magnification).

Fig. 10 Columnar cells from upper third showing increase in electron dense bodies. Goblet cells $(G)$ show variation in electron density of mucus granules ( $\times 4300$ original magnification).

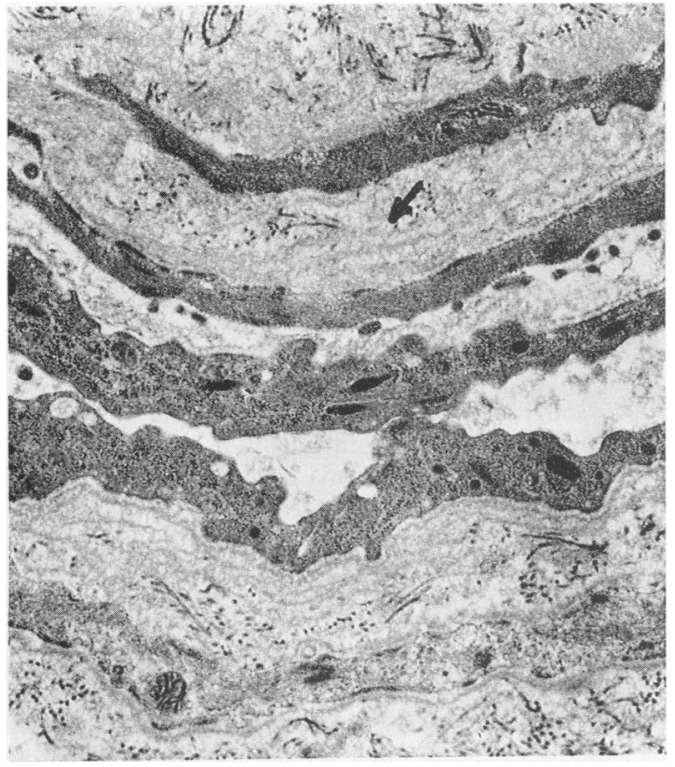

Fig. 11 Longitudinal section of a blood vessel showing prominent reduplication of basal lamella (arrow) $(\times 7100$ original magnification). study. ${ }^{20-22}$ The clinical significance of these organisms is not known although there are suggestions that they may give rise to rectal symptoms and increased vacuolation of rectal surface epithelial cells. ${ }^{2324}$ The spiral organisms present in southern Indian biopsies are likely to be a part of the altered flora of the colon reflected by the wide prevalence of pathogens in otherwise asymptomatic subjects. ${ }^{25}$ In the present series of subjects the presence of spiral organisms were not associated with any symptoms. Striking morphological alterations in colonocytes were found in subjects with and without spiral organisms. The nature of the injury responsible for these reactive changes is not clear but is likely to be because of a variety of intraluminal factors of which the microbial flora is only one.

Increased reticulin and activation of histiocytes and plasma cells in the lamina propria was a striking feature of these biopsies. In southern India, in addition to episodes of acute infectious diarrhoea asymptomatic infection by presumed pathogens is common $^{25}$ and there is also a high prevalence of enteroviruses (Patel and Mathan, unpublished). The 'reticulohistiocytic complex' of the submucosa of the colon is a primary defence against the microbial 


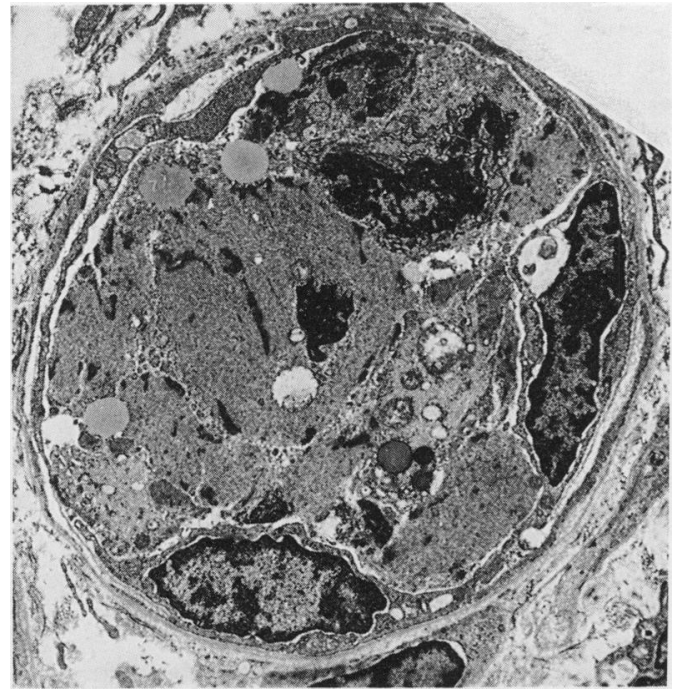

Fig. 12 Cross section of a blood vessel occluded by organised thrombus $(\times 4300$ original magnification $)$.

flora of the lumen ${ }^{5}$ and the observed changes are a response to the luminal environment in tropical countries.

The changes in the microvasculature with reduplication of the basal lamellae in scattered blood vessels in all the biopsies, organised thrombus in isolated vessels in three biopsies and evidence of endothelial damage and haemorrhage in one biopsy are similar to the vascular damage described in the jejunal mucosa in Crohn's disease. ${ }^{26}$ Similar vascular alterations were not found in at least three other careful studies of the rectal mucosal lamina propria in temperate zone controls. ${ }^{51127}$ We have found endothelial and platelet mediated vascular damage with intravascular thrombosis and basement membrane reduplication as a significant feature of severe episodes of acute diarrhoea in adults in this population (unpublished observations). As the average south Indian adult has at least one episode of acute diarrhoea every three years, it is reasonable to postulate that the vascular alterations found in all the biopsies may be the fingerprints of earlier diarrhoeal episodes.

The morphological alterations in the rectal mucosa of healthy volunteers in southern India described here suggest a response to non-specific injury similar to that in the small intestine in the tropics. They should be kept in mind in interpreting ultrastructural pathology in rectal mucosal biopsies. Further studies are necessary to delineate their geographic distribution, extent of colonic involve- ment and to understand the mechanism of pathogenesis in which the microbial flora, dietary constituents and factors as yet not understood may be important.

The Wellcome Research Unit is supported by The Wellcome Trust, London.

\section{References}

1 Baker SJ, Mathan VI. Tropical enteropathy and tropical sprue. Am J Clin Nutr 1972; 25: 1047-55.

2 Baker SJ. Geographical variations in the morphology of the small intestinal mucosa in apparently healthy individuals. Pathol Microbiol 1973; 39: 222-37.

3 Mathan M, Mathan VI, Baker SJ. An electron microscopiç study of jejunal mucosal morphology in control subjects and in patients with tropical sprue in southern India. Gastroenterology 1975; 68: 17-32.

4 Mathan VI, Ponniah J, Mathan M. Tropical enteropathy: an adaptation of the small intestine to accelerated cell loss in 'contaminated' environments. In: Robinson JWL, Dowling RH, Reicken EO, eds. Mechanisms of intestinal adaptation. Lancaster: MTP Press, 1982: 609-10.

5 Donnellan WL. The structure of colonic mucosa. The epithelium and subepithelial reticulohistocytic complex. Gastroenterology 1965; 49: 496-514.

6 Pittman FE, Pittman JC. An electron microscopic study of the epithelium of normal human sigmoid colonic mucosa. Gut 1966; 7: 644-61.

7 Nagle GJ, Kurtz SM. Electron microscopy of the human rectal mucosa. A comparison of idiopathic ulcerative colitis with inflammation of known aetiologies. Am J Dig Dis 1967; 12: 541-67.

8 Lorenzonn V, Trier JS. The fine structure of human rectal mucosa: the epithelial lining of the base of the crypt. Gastroenterology 1968; 55: 88-101.

9 Kaye GI, Fenoglio CM, Pascal RR, Lane N. Comparative electron microscopic features of normal, hyperplastic and adenomatous human colonic epithelium. Variations in cellular structure relative to the process of epithelial differentiation. Gastroenterology 1973; 64: 926-45.

10 Dawson PA, Filipe MI. An ultrastructural and histochemical study of the mucous membrane adjacent to and remote from carcinoma of the colon. Cancer 1976; 37: 2388-98.

11 Shamsuddin AM, Phelps PC, Trump BF. Human large intestinal epithelium. Light microscopy, histochemistry and ultrastructure. Human Pathol 1982; 13: 790-803.

12 Biempica L, Sternlieb I, Sohn HB, Ali M. R bodies of human rectal epithelial cells. Arch Pathol Lab Med 1976; 100: 78-80.

13 Eldrup E, Mollgard K, Bindslev N. Possible sodium channels in the luminal membrane of the hen lower intestine visualised by freeze fracture. In: Hormonal control of epithelial transport INSERM 1979; 85: 253-62. 
14 Neutra MR. Linear arrays of intramembrane particles on microvilli in primate large intestine. Anat Rec 1979; 193: $367-81$.

15 Mughal S, Filipe MI, Jass JR. A comparative ultrastructural study of hyperplastic and adenomatous polyps, incidental and in association with colorectal cancer. Cancer 1981; 48: 2746-55.

16 Schofield GC. Columnar cells with secretory granules in the large intestine. J Anat 1970; 106: 1-14.

17 Dawson PA, Filipe MI. Ultrastructural application of silver methanamine to the study of mucin changes in the colonic mucosa adjacent to and remote from carcinoma. Histochem J 1976; 8: 143-58.

18 Schofield GC, Atkins AM. Secretory immunoglobulin in columnar epithelial cells of large intestine. J Anat 1970; 107: 491-504.

19 Mughal S, Filipe M. Ultrastructural study of the normal mucosa-adenoma-cancer sequence in the development of familial polyposis coli. J Natl Cancer Inst 1978; 60: 753-68.

20 Macifie JW. The prevalence of Spirochaeta eurygyrata in Europeans and natives in the gold coast. Lancet 1917; 1: 336-40.
21 Lee FD, Kraszewski A, Gordon J, Howie JER, McSeverey D, Harland WA. Intestinal spirochaetosis. Gut 1971; 12: 126-33.

22 Takeuchi A, Jervis HR, Nakazawa H, Robinson DM. Spiral shaped organisms on the surface colonic epithelium of monkey and man. Am J Clin Nutr 1974; 27: 1287-96.

23 Harland WA, Lee FD. Intestinal spirochaetosis. Lancet 1967; 3: 718-9.

24 Crucioli V, Busuttil A. Human intestinal spirochaetosis. Scand J Gastroenterol 1981; 16: suppl 70: 177-9.

25 Rajan DP, Mathan VI. Prevalence of Campylobacter fetus subsp. jejuni in healthy populations in southern India. J Clin Microbiol 1982; 15: 749-51.

26 Dvorak AM, Monahan RA, Osage JE, Dickersin GR. Crohn's disease - transmission electron microscopic studies. II. Immunologic inflammatory response, alterations of mast cells, basophils, eosinophils and the microvasculature. Human Pathol 1980; 11: 606-19.

27 Eidelman S, Lagunoff D. The morphology of the normal human rectal biopsy. Human Pathol 1972; 3: 389-401. 